\title{
Relation between $\beta$-lactamase producing bacteria and patient characteristics in chronic obstructive pulmonary disease (COPD)
}

\author{
JH Sportel, G H Koëter, R van Altena, A Löwenberg, W G Boersma
}

\begin{abstract}
Background - In addition to bronchodilator and anti-inflammatory therapy, exacerbations in patients with chronic obstructive pulmonary disease (COPD) are often treated with antibiotics. Haemophilus influenzae and Moraxella (Branhamella) catarrhalis, two important respiratory pathogens, may produce $\beta$-lactamase which makes them resistant to ampicillin. Surveillance studies conducted in various countries have shown an increasing incidence of these $\beta$-lactamase producing bacteria. Although this may simply be a consequence of the increasing use of antibiotics, it is possible that other factors are important. A study was undertaken to investigate whether clinical factors are related to the presence of $\beta$ lactamase forming bacteria in the sputum of patients with COPD.
\end{abstract}

Methods - One hundred patients with COPD aged over 40 years were sequentially selected from an outpatient clinic on the basis of sputum culture results. Fifty had $\beta$-lactamase positive $(\beta \mathbf{L}+)$ and 50 had $\beta$-lactamase negative $(\beta L-)$ bacteria in their sputum. Patients were included only if sputum culture results yielded one pathogen. The files of these patients were investigated for possible causative factors present during the two preceding years.

Results - Both groups were almost identical in terms of lung function, maintenance medication, and smoking history. The total number of antibiotic courses in the $\mathbf{L}+$ group was higher, as were individual courses of cephalosporins, tetracyclines, and macrolides. The number of patients admitted to hospital was higher in the $\beta \mathbf{L}+$ group, but admissions were of equal duration in both groups. Patients admitted to hospital had poorer lung function. Risk factors for $\beta$-lactamase producing bacteria were identified by logistic regression analysis which revealed an odds ratio for one course of antibiotics of $1 \cdot 15$ (95\% CI 1.04 to $1 \cdot 28$ ).

Conclusions - An increased number of antibiotic courses is related to a higher incidence of $\beta$-lactamase producing bacteria and more patients had hospital admissions in the $\beta L+$ group. $\beta$-lactamase stable antibiotics were used more frequently in the $\beta \mathbf{L}+$ group, probably because prescribing was adapted to the presence of $\beta$-lactamase producing bacteria. No other differences were found between the $\beta \mathbf{L}+$ and $\beta \mathbf{L}-$ groups.

(Thorax 1995;50:249-253)

Keywords: $\beta$-lactamase producing bacteria, chronic obstructive pulmonary disease.

Patients with chronic obstructive pulmonary disease (COPD) frequently have exacerbations, especially during the winter season. These exacerbations are characterised by increased dyspnoea, cough, sputum volume, and/or increased purulence of sputum. ${ }^{1}$ Patients with an exacerbation of COPD are usually treated with antibiotics as well as bronchodilators and corticosteroids. Although antibiotics should ideally be selected according to bacterial isolates, in general treatment is often empirical.

Since the late 1970 s there has been an increasing incidence of respiratory pathogens resistant to ampicillin. ${ }^{2-4}$ In a European collaborative study resistance of Haemophilus influenzae to ampicillin varied from $0.5 \%$ in Austria to $31.1 \%$ in Spain. ${ }^{5}$ An American study reported an incidence of $20 \%$ of $H$ influenzae strains resistant to ampicillin. ${ }^{6}$ Resistance to ampicillin for Moraxella (Branhamella) catarrhalis has been reported in up to $73 \%$ of cases. ${ }^{7}$ This resistance, due mostly to $\beta$-lactamase production, has a major impact on the efficacy of antibiotics in lower respiratory tract infection. ${ }^{28-10}$

Beta-lactamases are enzymes produced by bacteria which inactivate $\beta$-lactam antibiotics by cleavage of the $\beta$-lactam ring. This is an oversimplification, since different types of $\beta$ lactamase and different types of spread and induction of $\beta$-lactamase can be recognised. The most important $\beta$-lactamase in $H$ influenzae is TEM-1 $\beta$-lactamase which is transferred by plasmids. ${ }^{11}$ In $M$ catarrhalis the most important $\beta$-lactamases are $\mathrm{BRO}-1$ or $\mathrm{BRO}-2$, whose origins remain unknown. ${ }^{8}$ The effect of the presence of $\beta$-lactamase is that an individual bacterium or the entire colony becomes resistant to $\beta$-lactamase unstable antibiotics.

One factor that could contribute to the increasing rate of $\beta$-lactamase producing bacteria in patients with COPD is antibiotic treatment which causes selection of resistant $\beta$-lactamase producing strains. However, other factors, related to the individual patient, might also contribute to the presence of $\beta$-lactamase producing bacteria. In this retrospective study we have investigated whether support could be found for this hypothesis. 


\section{Methods}

PATIENTS

One hundred patients with COPD were selected from the pulmonary outpatient clinic of Hospital Beatrixoord, Haren, The Netherlands on the basis of sputum culture results, 50 patients with $\beta$-lactamase-producing bacteria $(\beta \mathrm{L}+$ group) and 50 with bacteria that were not $\beta$-lactamase producing ( $\beta \mathrm{L}-$ group). In all cases only a single pathogen was isolated, and patients were excluded when more than one pathogen was cultured. All patients were in a stable phase of their disease. Patients were over 40 years of age and none had a history of allergy. The patients' files were retrospectively studied for the preceding two years to acquire data for the following characteristics: age, gender, duration of disease, smoking history, lung function, type and dosage of maintenance medication, hospital admission rate, and duration of hospital stay.

\section{SPUTUM}

Patients attending the clinic routinely delivered sputum in a sterile plastic jar at each visit. The sputum was washed three times in sterile saline to remove saliva and oropharyngeal flora. ${ }^{12} \mathrm{Af}-$ ter Gram staining the sputum fragments were examined microscopically. ${ }^{13}{ }^{14}$ When fewer than five epithelial cells and more than 25 leucocytes were counted per low power field $(100 \times$ magnification) the sputum was considered representative of the lower respiratory tract. ${ }^{15-17}$ Representative sputum specimens only were then cultured semiquantitatively according to accepted methods using blood agar, Leventhal's agar, and McConkey's medium, and incubated for 24 hours at $37^{\circ} \mathrm{C}$. Susceptibility to antibiotics was tested by an agar dilution method using standard criteria. When resistance to ampicillin was shown an indicator test with nitrocephin (Cefinase, BBL Microbiology Systems, Becton Dickinson and Co, Cockeysville, USA) was applied for detection of $\beta$-lactamase activity.

\section{LUNG FUNCTION}

During the consultation inspiratory vital capacity (IVC) and forced expiratory volume in one second $\left(\mathrm{FEV}_{1}\right)$ were measured twice in a standard manner ${ }^{18-20}$ using a Pneumoscope (Jaeger, Breda, The Netherlands). Measurements were made at least four hours after any inhaled bronchodilators. The higher results of both IVC and FEV 1 were used.

\section{DURATION OF DISEASE}

The duration of disease was calculated by subtracting the date on which the patient was diagnosed as having COPD from the date of the visit to the outpatient clinic.

\section{MAINTENANCE MEDICATION}

Information on maintenance treatment was retrieved from the next to last letter addressed to the general practitioners; the type of med- ication as well as the daily dosage in $\mathrm{mg}$ per day was noted.

\section{NUMBER OF ANTIBIOTIC COURSES}

The patients' general practitioners and pharmacists were telephoned in order to assess the number and type of antibiotic courses that had been prescribed. Data on antibiotic courses prescribed by respiratory physicians were derived from the hospital files.

\section{SMOKING}

The following definitions were used: "nonsmokers" were patients who had never smoked; "ex-smokers" were patients who stopped smoking before the beginning of the study period. Exposure was expressed as pack-years.

\section{ADMISSIONS TO HOSPITAL}

The admission rate was assessed by counting the number of hospital admissions in the two years preceding the visit to the outpatient department. The duration of each admission and the total duration of all admissions in these two years were noted.

\section{STATISTICAL ANALYSIS}

The Student's $t$ test was used for normally distributed variables, the Mann-Whitney U test for not normally distributed and categorical variables, and the $\chi^{2}$ test for dichotomous variables. The statistical software package SPSS/ PC +, V4.0.1 (SPSS Inc, Chicago, Illinois, USA) was used. Logistic regression analysis was performed to build a model that could predict the presence of $\beta$-lactamase-producing bacteria. For this and for computation of odds ratios and confidence intervals the computer program Statistix (Analytical Software, St Paul, Minnesota, USA) was used. Variables that would not fit in the model according to known criteria were forced into the model when they seemed biologically important. ${ }^{21} \mathrm{~A} p$ value of $<0.05$ was considered significant.

\section{Results}

The patients analysed in this study were enrolled over a period of 20 consecutive months. During this period 1843 individual patients visited the outpatient clinic at least once, of whom $580(31 \%)$ produced sputum. Sputum was cultured on 960 occasions and revealed pathogens in $389(40 \%)$ of cultures. Of the enrolled patients, all produced sputum chronically, most had airflow limitation, and $60 \%$ were smokers.

\section{SPUTUM}

The results of sputum cultures are summarised in table $1 ; 77$ of 100 isolates contained $H$ influenzae or $M$ catarrhalis. $\beta$-lactamase producing strains were found in 33 of $42(79 \%)$ $M$ catarrhalis strains and five of $35(14 \%) H$ influenzae strains. 
Table 1 Isolated pathogens and number (\%) of $\beta$-lactamase producing strains in the sputum of 100 patients with COPD

\begin{tabular}{lcc}
\hline Pathogen & No found & No (\%) B-lactamase positive \\
\hline M catarrhalis & 42 & $33(79)$ \\
H influenzae & 35 & $5(14)$ \\
Str pneumoniae & 10 & $-7(100)$ \\
Ps aeruginosa & 7 & $2(100)$ \\
Staph aureus & 2 & $2(100)$ \\
E coli & 2 & 1 \\
Acinetobacter calcoaceticus & 2 & 50 \\
Total & 100 & 50 \\
\hline
\end{tabular}

\section{PATIENT CHARACTERISTICS}

Both patient groups were comparable for most characteristics (table 2). Significantly more patients in the $\beta \mathrm{L}+$ group had been admitted to hospital in the preceding two years, but the total number of admissions and the duration of those admissions were similar. Patients who had been admitted once or more in the past two years used more antibiotic courses (median (range) $10(2-25)$ ) with a total of 262 courses to the 27 patients admitted compared with 3 (0-20) with a total of 323 antibiotic courses to the 73 not admitted). The patients admitted to hospital had poorer lung function (both
$\mathrm{FEV}_{1} \%$ pred and IVC $\%$ pred $\left.\mathrm{p} \leqslant 0 \cdot 005\right)$. There were no differences between the $\beta \mathrm{L}-$ and $\beta \mathrm{L}+$ patients who had been admitted with regard to their number of antibiotic courses or their lung function.

\section{MAINTENANCE MEDICATION}

The different types of maintenance medication used by patients of both groups are listed in table 3. There were no significant differences.

\section{ANTIBIOTIC TREATMENT}

There was a wide interindividual range in the number of antibiotic courses during the two year period (table 4). More antibiotic courses were used by patients in the $\beta \mathrm{L}+$ group ( $\mathrm{p}=$ $0.005)$ and this applied to cephalosporins $(p<$ $0.05)$, tetracyclines $(p<0.05)$, and macrolides $(p<0.005)$. The individual patients in the $\beta \mathrm{L}+$ group also had more courses of tetracycline than those in the $\beta L-$ group ( $p<0.005)$. Thirteen patients were on maintenance antibiotic treatment, eight in the $\beta \mathrm{L}+$ group and five in the $\beta \mathrm{L}$ - group (NS).

Table 2 Characteristics of patients in the study population

\begin{tabular}{|c|c|c|c|}
\hline Characteristic & $\beta L+$ & $\beta L-$ & $p$ \\
\hline 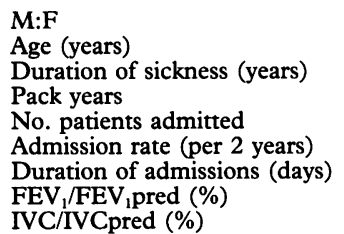 & $\begin{array}{l}36 / 14 \\
65(40-85) \\
20(1-62) \\
17 \cdot 4(4 \cdot 8-56 \cdot 0) \\
18 \\
1 \cdot 5(1-6) \\
22(5-65) \\
47 \cdot 2(20 \cdot 8-122 \cdot 7) \\
71 \cdot 8(35 \cdot 5-135 \cdot 1)\end{array}$ & $\begin{array}{l}38 / 12 \\
66(40-83) \\
17(3-61) \\
19 \cdot 6(1 \cdot 1-45) \\
9 \\
2(1-6) \\
18(12-49) \\
52 \cdot 5(16 \cdot 4-116 \cdot 1) \\
83 \cdot 2(31 \cdot 5-113 \cdot 6)\end{array}$ & $\begin{array}{l}\text { NS* } \\
\text { NS } \dagger \\
\text { NS† } \\
\text { NS† } \\
<0 \cdot 005^{*} \\
\text { NS† } \\
\text { NS† } \\
\text { NS† } \\
\text { NS† }\end{array}$ \\
\hline
\end{tabular}

$\beta \mathrm{L}+=\beta$-lactamase positive; $\beta \mathrm{L}-=\beta$-lactamase negative.

$* \chi^{2}$ test.

† Mann-Whitney U test.

Values are median (range).

Table 3 Number of patients on different types of maintenance medication

\begin{tabular}{|c|c|c|c|c|c|}
\hline \multirow[t]{2}{*}{ Medication } & \multicolumn{2}{|c|}{$\beta L+(n=50)$} & \multicolumn{2}{|c|}{$\beta L-(n=50)$} & \multirow[b]{2}{*}{$p$} \\
\hline & $n$ & $\begin{array}{l}\text { Median (range) daily } \\
\text { dosage (mg/day) }\end{array}$ & $n$ & $\begin{array}{l}\text { Median (range) daily } \\
\text { dosage (mg/day) }\end{array}$ & \\
\hline Prednisolone & 11 & $5 \cdot 0(2 \cdot 5-10 \cdot 0)$ & 16 & $7 \cdot 5(2 \cdot 5-20 \cdot 0)$ & NS \\
\hline Inhaled corticosteroids & 44 & $0 \cdot 8(0 \cdot 1-1 \cdot 6)$ & 42 & $0 \cdot 7(0 \cdot 2-3 \cdot 2)$ & NS \\
\hline Oral $\beta$ sympathicomimetics & 5 & $10(5-10)$ & 6 & $6 \cdot 25(5-10)$ & NS \\
\hline Inhaled $\beta$ sympathicomimetics & 38 & $0.8(0 \cdot 2-15 \cdot 0)$ & 32 & $0 \cdot 6(0 \cdot 1-2 \cdot 8)$ & NS \\
\hline Anticholinergics & 41 & $0 \cdot 16(0.02-3 \cdot 00)$ & 45 & $0 \cdot 10(0 \cdot 02-0 \cdot 4)$ & NS \\
\hline Theophylline & 23 & $450(200-900)$ & 15 & $450(200-900)$ & NS \\
\hline
\end{tabular}

Table 4 Numbers of patients using the different antibiotics, with those on penicillins and cephalosporins subdivided into $\beta$-lactamase ( $\beta L$ ) stable and unstable groups, and the numbers of antibiotic courses used during the last two years

\begin{tabular}{|c|c|c|c|c|c|c|}
\hline \multirow[t]{3}{*}{ Antibiotic } & \multicolumn{2}{|l|}{ No. of patients } & \multicolumn{4}{|c|}{ No. of courses } \\
\hline & \multirow[t]{2}{*}{$\beta L+(n=50)$} & \multirow[t]{2}{*}{$\beta L-(n=50)$} & \multicolumn{2}{|c|}{$\beta L+(n=50)$} & \multicolumn{2}{|c|}{$\beta L-(n=50)$} \\
\hline & & & Total & Median (range) & Total & Median (range) \\
\hline $\begin{array}{l}\text { Penicillins } \\
\beta L \text { stable } \\
\beta L \text { unstable } \\
\text { Cephalosporins } \\
\beta L \text { stable } \\
\beta L \text { unstable } \\
\text { Tetracyclines } \\
\text { Macrolides } \\
\text { Cotrimoxazole } \\
\text { Aminoglycosides } \\
\text { Quinolones } \\
\text { Unknown }\end{array}$ & $\begin{array}{l}35 \\
13 \\
29 \\
13^{*} \\
7^{*} \\
8 \\
32^{*} \\
13^{*} \\
19 \\
4 \\
6 \\
14\end{array}$ & $\begin{array}{r}26 \\
8 \\
24 \\
4 \\
1 \\
3 \\
21 \\
4 \\
12 \\
\overline{3} \\
18\end{array}$ & $\begin{array}{l}115 \\
23 \\
90 \\
30 \\
15 \\
15 \\
94^{* *} \\
32 \\
32 \\
7 \\
10 \\
46\end{array}$ & $\begin{array}{l}2(1-10) \\
1(1-8) \\
2(1-10) \\
2(1-8) \\
1(1-7) \\
1 \cdot 5(1-4) \\
3(1-11) \\
2(1-6) \\
1(1-5) \\
1 \cdot 5(1-2) \\
1 \cdot 5(1-3) \\
2 \cdot 5(1-8)\end{array}$ & $\begin{array}{r}87 \\
15 \\
71 \\
10 \\
3 \\
7 \\
37 \\
13 \\
20 \\
- \\
6 \\
43\end{array}$ & $\begin{array}{l}3(1-7) \\
2(1-4) \\
3(1-7) \\
2 \cdot 5(1-4) \\
- \\
2(1-4) \\
1(1-8) \\
1(1-10) \\
1(1-4) \\
\overline{2}(1-3) \\
1(1-6)\end{array}$ \\
\hline Total & 50 & 50 & $366^{* *}$ & $6(1-25)$ & 219 & $3(1-20)$ \\
\hline
\end{tabular}

${ }^{*} \mathrm{p}<0 \cdot 05, \chi^{2}$ test; ${ }^{* *} \mathrm{p}<0 \cdot 005$, Mann-Whitney U test. 
Table 5 Odds ratios and confidence intervals (95\% CI) for predictive variables for $\beta$ lactamase production

\begin{tabular}{llll}
\hline Predictive variables & Odds ratio & (95\% CI) & $p$ \\
\hline Age (years) & 0.99 & $(0.94$ to 1.03$)$ & NS \\
Duration of sickness (years) & 1.00 & $(0.97$ to 1.04$)$ & NS \\
Gender (male) & 0.99 & $(0.34$ to 2.86$)$ & NS \\
FEV (\% predicted) & 0.99 & $(0.97$ to 1.02$)$ & NS \\
IVC (\% predicted) & 1.01 & $(0.98$ to 1.04$)$ & NS \\
No antibiotic courses (per 1) & 1.15 & $(1.04$ to 1.28$)$ & $<0.01$ \\
No antibiotic courses (per 10) & 4.07 & $(1.43$ to 11.56$)$ & $<0.01$ \\
\hline
\end{tabular}

$\mathrm{FEV}_{1}=$ forced expiratory volume in one second; $\mathrm{IVC}=$ inspiratory vital capacity.

Penicillins and cephalosporins were divided into $\beta$-lactamase stable and unstable antibiotics. No differences were found for $\beta$ lactamase stable and unstable penicillins, and $\beta$-lactamase unstable cephalosporins. $\beta$ lactamase stable cephalosporins were used by more patients in the $\beta \mathrm{L}+$ group $(\mathrm{p}<0.05)$.

$\beta$-lactam antibiotics were not used more often for the last course than non- $\beta$-lactam antibiotics.

\section{LOGISTIC REGRESSION ANALYSIS}

It appeared that few variables would fit the model. The results of our analysis (odds ratios (OR) and 95\% confidence intervals (CI)) are shown in table 5 in which are also displayed $\mathrm{OR}$ and $\mathrm{CI}$ for 10 antibiotic courses. A higher number of antibiotic courses in the past two years increased the chance of having a $\beta$-lactamase-producing bacterium in the sputum.

\section{Discussion}

Streptococcus pneumoniae, $H$ influenzae, and $M$ catarrhalis are known to be major respiratory pathogens in COPD. ${ }^{223}$ In this study $H$ influenzae and $M$ catarrhalis were also the most frequently isolated single pathogens, in frequencies similar to those of other studies. ${ }^{57}$ The same is true for the frequency of Str pneumoniae (20\%). By selection bias Str pneumoniae was only included in the $\beta \mathrm{L}$ - group. Resistance of Str pneumoniae to ampicillin is not associated with $\beta$-lactamase but is caused by changes in penicillin binding proteins.

The prevalence of resistance of airway pathogens, especially $H$ influenzae and $M$ catarrhalis, is increasing, ${ }^{23-72425}$ mainly because of $\beta$ lactamase which causes resistance to ampicillin. $^{2311}$ In 1989 surveillance cultures performed in the same study population yielded $H$ influenzae in $57 \%(\beta \mathrm{L}+9 \%), M$ catarrhalis in $23 \%(\beta \mathrm{L}+57 \%)$, and Str pneumoniae in $21 \%{ }^{26}$ In this study we confirm that this increased resistance is associated with the increased use of antibiotics. ${ }^{97-29}$ We have considered the possibility that patient related factors may also contribute to this resistance.

In the present study more antibiotic courses were taken by patients in the $\beta \mathrm{L}+$ group than by those in the $\beta \mathrm{L}-$ group. Patients who had been admitted, both in the $\beta \mathrm{L}-$ and $\beta \mathrm{L}+$ groups, had poorer lung function and had received more antibiotic courses than the others. This may be explained by the fact that patients with poor lung function seem to suffer more severely during exacerbations. ${ }^{30}$ Thus, respiratory physicians and general practitioners prescribe antibiotics and admit their patients more readily than when lung function is better.

The fact that more patients in the $\beta \mathrm{L}+$ group used tetracyclines and $\beta \mathrm{L}$ stable cephalosporins, and that more courses of tetracyclines were used in the $\beta \mathrm{L}+$ group, can be explained as follows. We found that the sputum culture results were mentioned in most correspondence to general practitioners and these were noted, resulting in the prescription of an effective antibiotic. An alternative explanation could be that general practitioners and respiratory physicians noticed poor results from empirical antibiotic prescribing, and that $\beta \mathrm{L}$ stable antibiotics had a favourable effect. However, we would then have also expected more $\beta$-lactamase sensitive antibiotics to have been prescribed. It is known that there is a wide interindividual range in the frequency of exacerbations, ${ }^{30}$ thus patients in the $\beta \mathrm{L}+$ group were more likely to have a higher frequency of exacerbations. If this did occur the reason for it remains unclear, although various explanations are possible - for example, a greater bronchial hyperresponsiveness or, for some reason, less optimal anti-COPD treatment with corticosteroids and/or bronchodilators.

The higher frequency of exacerbations in the $\beta \mathrm{L}+$ group eventually results in the use of more courses of antibiotics. However, with frequent usage of antibiotics $\beta$-lactamase producing bacteria are being selected ${ }^{527-29}$ and, in studies in children with upper and lower respiratory tract infections caused by $H$ influenzae both type b and non-b, more resistant strains were found in those who had recently been treated with antibiotics. ${ }^{272931}$ In neither study were patients suffering from any underlying disease, and the study period lasted up to seven ẃeeks. ${ }^{29} \mathrm{Al}-$ though these studies are not strictly comparable with the present report on older patients with COPD who were studied retrospectively for two years, the findings are similar to ours that is, increasing use of antibiotics is related to isolation of more $\beta$-lactamase producing strains. This is also supported by the results of our logistic regression analysis. Some studies have also shown that there is a relation with the type of antibiotic prescribed, ${ }^{2729}$ which is in contrast to our findings. Wallace et al studied $H$ influenzae resistance to ampicillin, tetracycline, and chloramphenicol in adults with chronic lung disease. ${ }^{9}$ Their results showed that patients with resistant strains were more likely to have received antibiotics recently.

The presence of $\beta$-lactamase producing bacteria may be considered as an end point in a pathogenetic chain, in parallel with the colonisation of the respiratory tract in patients with cystic fibrosis or severe bronchiectasis by Pseudomonas aeruginosa. It is, however, possible that the presence of $\beta$-lactamase producing strains is a cause, rather than a consequence, of the higher exacerbation rate. One could speculate that this would imply that $\beta$-lactamase producing strains from the same species present a more virulent biological behaviour than non- $\beta$-lactamase producing strains. Pro- 
spective studies are needed to test these hypotheses.

We are aware of certain drawbacks of this retrospective study. Firstly, the maintenance medication was assessed only at the end point of the study period and we have no information on previous changes of treatment or compliance. Secondly, we do not know the exact dosage and duration of the antibiotic courses, nor do we know what criteria were used for prescribing antibiotics or whether they were prescribed in combination with prednisolone. Thirdly, the lung function tests may not have been representative of the entire two year period. Data on decline in lung function and reversibility were not available for all patients. Fourthly, and more importantly, we do not know if the sputum culture results are representative for the whole two year period. From other studies we think that in most patients they were since it has been shown that the same bacteria can be isolated from the sputum for a long period. ${ }^{3233}$ Finally, by screening for clinically suggestive characteristics we were not able to identify reliably patients with bronchiectasis. Objective measures (high resolution computed tomographic scanning and bronchography) for the diagnosis of bronchiectasis were not available in most files. However, we would have expected patients with bronchiectasis to be distributed equally between both groups, and the number of patients with extensive bronchiectasis is likely to be very low.

In conclusion, we have shown that more frequent antibiotic use is associated with a higher chance of the presence of $\beta$-lactamase producing bacteria in the sputum of patients with COPD. A prospective study is necessary to confirm our data and hypotheses. In such a study other factors such as changes in maintenance medication, the causal stimuli of exacerbations, bronchial hyperresponsiveness, and the extent of anatomical destruction of airways and lung tissue need to be analysed.

Since we need to prevent any further increase in the prevalence of resistance to antibiotics, not only due to $\beta$-lactamase production, we should be aware of the risks in prescribing them. Patients with a high exacerbation rate should be identified and efforts made to prevent them. However, when antibiotic treatment is considered imperative it should be given on a valid indication. Adequate microbiological identification and assessment of antibiotic resistance are desirable parameters, on the basis of which optimal antibiotic treatment can be initiated.

1 American Thoracic Society. Standards for the diagnosis and care of patients with chronic obstructive pulmonary diseas (COPD) and asthma. Am Rev Respir Dis 1987;136:225-44

2 Neu HC. Contribution of beta-lactamases to bacterial resistance and mechanisms to inhibit beta-lactamases. $A m$ f Med 1985;79:2-12.

3 Neu HC, Chin NX. A perspective on the present contribution of beta-lactamases to bacterial resistance with particular reference to induction of beta-lactamase and its clinical significance. Chemioterapia 1985;4:63-70.

4 Philpott-Howard J, Williams JD. Increase in antibiotic resistance in Haemophilus influenzae in the United Kingdom sistance in Haemophilus influenzae in the United Kingdom
since 1977: report of study group. BMF 1982;284:1597-9.

5 Kayser FH, Morenzoni G, Santanam P. The second European collaborative study on the frequency of antimicrobial resistance in Haemophilus influenzae. Eur $\mathcal{f}$ Clin Micnobiol Infect Dis 1990;9:810-7.

6 Doern GV, Jorgensen JH, Thornsberry C, Preston DA Tubert T, Redding JS, et al. National collaborative study of the prevalence of antimicrobial resistance among clinical isolates of Haemophilus influenzae. Antimicrob Agents Chemother 1988;32:180-5.

7 Nicotra B, Rivera M, Luman JI, Wallace RJ Jr. Branhamella catarrhalis as a lower respiratory tract pathogen in patients with chronic lung disease. Arch Intern Med 1986;146: 890-3.

8 Wallace RJ, Jr, Nash Dr, Steingrube VA. Antibiotic susceptibilities and drug resistance in Moraxella (Branhamella) catarhalis. Am $\mathcal{f}$ Med 1990;88(Suppl 5A): 46-50S

9 Wallace RJ, Jr, Steele LC, Brooks DL, Forrester GD, Garcia $\mathrm{JG}$, Luman JI, et al. Ampicillin, tetracycline, and chloramphenicol resistant Haemophilus influenzae in adults with chronic lung disease. Relationship of resistance to prior antimicrobial therapy. Am Rev Respir Dis 1988;137:695-9.

10 Neu HC. The role of beta-lactamase inhibitors in chemotherapy. Pharmacol Ther 1985;30:1-18.

11 Needham CA. Haemophilus influenzae: antibiotic susceptibility. Clin Microbiol Rev 1988;1:218-27.

12 Mulder J. Clinical significance of bacteriologic examination of sputum in cases of acute and chronic bacterial disease of respiratory tract. In: Dock W, Snapper I, eds. Advances in internal medicine. Chicago: Year Book Medical Publishers, 1964:233-55.

13 Mulder J. Bacteriology of bronchitis I. Chronic bronchitis. Proc $R$ Soc Med 1956;49:773-5.

14 Kalin M. Bacteriemic pneumococcal pneumonia: value of culture of nasopharyngeal specimens and examination of culture of nasopharyngeal specimens and examination of washed

15 Van Scoy RE. Bacterial sputum cultures. Mayo Clin Proc 1977;52:39-41.

16 Murray PR, Washington II JA. Microscopic and bacteriologic analysis of expectorated sputum. Mayo Clin Proc 1975;50:339-44.

17 Kalin M, Lindberg AA, Tunevall G. Etiological diagnosis of bacterial pneumonia by gram stain and quantitative culture of expectorates: leukocytes or alveolar macrophages as indicators of sample representativity. Scand $\mathcal{F}$ phages as indicators of sam $1983 ; 15: 153-60$.

18 Quanjer PH, Tammeling GJ, Cotes JE, Pedersen OF, Peslin $\mathrm{R}$, Yernault J-C. Lung volumes and forced ventilatory flows. Report working party standardization of lung function tests European Community for Steel and Coal. Official statement of the European Respiratory Society. Eur Respir f 1993;6(Suppl 16): 5-40.

19 American Thoracic Society. Standardization of spirometry 1987 update. Am Rev Respir Dis 1987;136:1285-98.

20 Ng'Ang'a LW, Ernst P, Jaakkola MS, Gerardi G, Hanley JH, Becklake MR. Spirometric lung function. Distribution and determinants of test failure in a young adult population. Am Rev Respir Dis 1992;145:48-52.

21 Hosmer DW, Lemeshow S. Applied logistic regression. New York: John Wiley, 1989.

22 Davies BI, Maesen FP. The epidemiology of respiratory tract pathogens in southern Netherlands. Eur Respir $f$ 1988;1:415-20.

23 Chodosh S. Acute bacterial exacerbations in bronchitis and asthma. Am F Med 1987;82:154-63.

24 Machka K, Braveny I, Dabernat H, Dornbusch K, van Dyck E, Kayser FH, et al. Distribution and resistance patterns of Haemophilus influenzae: a European cooperative study. Eur f Clin Microbiol Infect Dis 1988;7:14-24.

25 Doern GV, Jorgensen JH, Thornsberry C, Preston DA Prevalence of antimicrobial resistance among clinical isolates of Haemophilus influenzae: a collaborative study. Diagn Microbiol Infect Dis 1986;4:95-107.

26 Boersma WG, Löwenberg A, Koëter GH. Huidige inzichten betreffende antibiotische behandeling bij CARApatiënten. Ned Tijdschr Geneeskd 1994;138:1413-7.

27 Syriopoulou V, Sheifele D, Smith AL, Perry PM, Howie V. Increasing incidence of ampicillin resistance in Haemophilus influenzae. $\mathcal{F}$ Pediatr 1978;92:889-92.

28 Kaplan SL, Mason EA, Kvernland SJ. Effect of prior antibiotics on the susceptibility of Haemophilus influenzae type b to ampicillin. Pediatrics 1981;67:269-71.

29 Stephenson WP, Doern G, Gantz N, Lipworth L, Chapin K. Pharyngeal carriage rates of Haemophilus influenzae, type $b$ and non- $b$, and prevalence of ampicillin-resistant Haemophilus influenzae among healthy day-care children in Haemophilus influenzae among healthy day-care children in

30 Anthonisen NR, Manfreda J, Warren CP, Hershfield ES, Harding GK, Nelson NA. Antibiotic therapy in exacerbations of chronic obstructive pulmonary disease. Ann Intern Med 1987;106:196-204.

31 Timsit J-F, Misset B, Francoual S, Goldstein FW, Vaury P, Carlet J. Is protected specimen brush a reproducible method to diagnose ICU-acquired pneumonia? Chest 1993;104:104-8.

32 Groeneveld K, van Alphen L, Eijk PP, Visschers G, Jansen HM, Zanen HC. Endogenous and exogenous reinfections by Haemophilus influenzae in patients with chronic obstructive pulmonary disease: the effect of antibiotic treatstructive pulmonary disease: the effect of antibiotic
ment on persistence. $\mathcal{F}$ Infect Dis 1990;161:512-7.

33 Calder MA, Schonell ME. Pneumococcal typing and the problem of endogenous or exogenous reinfection in chronic bronchitis. Lancet 1971;i:1156-9. 